\title{
Endobronchial Valve Treatment in Emphysema Patients with a Very Low DLCO
}

\author{
Marlies van Dijk Jorine E. Hartman Karin Klooster Nick H.T. Ten Hacken \\ Huib A.M. Kerstjens Dirk-Jan Slebos \\ University of Groningen, Department of Pulmonary Diseases, University Medical Center Groningen, \\ Groningen Research Institute for Asthma and COPD, Groningen, The Netherlands
}

\section{Keywords \\ Chronic obstructive pulmonary disease - Endobronchial valve treatment - Bronchoscopic lung volume reduction . Diffusing capacity}

\begin{abstract}
Background: For selected patients with severe emphysema, bronchoscopic lung volume reduction with endobronchial valves (EBV) is recognized as an additional treatment option. In most trials investigating EBV treatment, patients with a very low diffusing capacity (DLCO) were excluded from participation. Objectives: Our goal was to investigate whether EBV treatment in patients with emphysema with a very low DLCO is safe and effective. Methods: This was a single-center retrospective analysis including patients with emphysema and a DLCO $\leq 20 \%$ pred who underwent EBV treatment. Follow-up was performed 6 months post-treatment. Outcome parameters were compared to a historical matched control group (DLCO > 20\%pred, matched for sex, age, forced expiratory volume in $1 \mathrm{~s}\left[\mathrm{FEV}_{1}\right]$, and residual volume $\left.[\mathrm{RV}]\right)$. Results: Twenty patients ( $80 \%$ female, $64 \pm 6$ years, $\mathrm{FEV}_{1} 26 \pm 6 \%$ pred, RV $233 \pm 45 \%$ pred, DLCO $18 \pm 1.6 \%$ pred) underwent EBV treatment. At 6 months follow-up, we found a statistically
\end{abstract}

significant improvement in $\mathrm{FEV}_{1}(0.08 \pm 0.12 \mathrm{~L}), \mathrm{RV}(-0.45 \pm$ $0.95 \mathrm{~L}), 6$-min walking distance ( $38 \pm 65 \mathrm{~m})$, and St. George's Respiratory Questionnaire ( $-12 \pm 13$ points). With the exception of FEV 1 , all exceeded the minimal clinically important difference. The most common serious adverse event was a pneumothorax requiring intervention (15\%). There were no significant differences in outcome compared to the DLCO $>20 \%$ pred control group. Conclusions: In this single-center retrospective analysis, we showed statistically significant and clinically relevant improvements in lung function, exercise capacity, and quality of life up to 6 months after EBV treatment in emphysema patients with a DLCO $\leq 20 \%$ (14$20 \%$ ) of predicted with no increased risk of serious adverse events.

(C) 2020 The Author(s) Published by S. Karger AG, Basel

\section{Introduction}

In advanced chronic obstructive pulmonary disease (COPD), breathlessness, impaired exercise capacity, and poor quality of life are common despite optimal standard therapy [1]. For selected patients with advanced COPD, bronchoscopic lung volume reduction with endobron-

\begin{tabular}{|c|c|}
\hline KARGER & $\begin{array}{l}\text { (C) } 2020 \text { The Author(s) } \\
\text { Published by S. Karger AG, Basel }\end{array}$ \\
\hline $\begin{array}{l}\text { E-Mail karger@karger.com } \\
\text { www.karger.com/res }\end{array}$ & $\begin{array}{l}\text { This article is licensed under the Creative Commons Attribution- } \\
\text { NonCommercial-NoDerivatives } 4.0 \text { International License (CC BY- } \\
\text { NC-ND) (http://www.karger.com/Services/OpenAccessLicense). } \\
\text { Usage and distribution for commercial purposes as well as any dis- } \\
\text { tribution of modified material requires written permission. }\end{array}$ \\
\hline
\end{tabular}

Marlies van Dijk, MD

Department of Pulmonary Diseases, AA11

University Medical Center Groningen

PO Box 30001, NL-9700 RB Groningen (The Netherlands)

E-Mail m.van.dijk05@umcg.nl 
chial valves (EBV) is recognized as an additional treatment option [2]. Prerequisites for this treatment are the presence of emphysema, severe hyperinflation, and absence of collateral ventilation between the target lobe and ipsilateral lobe(s) [3]. EBV treatment has emerged in recent years as a less invasive alternative for lung volume reduction surgery and has been shown to improve lung function, exercise capacity, and quality of life [4-8].

In most research investigating EBV treatment, patients with a very low diffusing capacity of the lungs for carbon monoxide (DLCO) were excluded from participating. This is mostly due to the results of the National Emphysema Treatment Trial (NETT), a large international multicenter trial comparing lung volume reduction to standard of care, where a subgroup of high-risk patients was identified with an increased postoperative mortality rate $[9,10]$. These high-risk patients were defined by having a forced expiratory volume in $1 \mathrm{~s}\left(\mathrm{FEV}_{1}\right)$ of $20 \%$ or less of the predicted value combined with either a homogeneous distribution of emphysema or a DLCO of $\leq 20 \%$ of predicted (\%pred). However, a recent retrospective trial investigating lung volume reduction surgery in patients with a DLCO of $<20 \%$ pred showed positive effects of treatment with no increased mortality rate (90-day mortality $0 \%)[11]$.

To our knowledge, no study evaluating outcomes in patients with a very low DLCO undergoing EBV-treatment has been published so far. Our goal was to investigate whether patients with COPD and a very low DLCO have the same clinical benefits as patients with a DLCO above 20\%pred and whether these patients are at increased risk of serious adverse events (SAEs). Furthermore, in the group of patients with a very low DLCO, we performed subanalyses for multiple patient characteristics relating to reduced oxygen uptake and emphysema distribution to assess whether these were associated with differences in outcome of EBV treatment.

\section{Material and Methods}

\section{Study Design and Population}

This was a single-center retrospective analysis including patients with COPD and a DLCO $\leq 20 \%$ pred who underwent bronchoscopic lung volume reduction with EBV at our hospital between April 2016 and October 2018. All patients with a DLCO $\leq 20 \%$ pred who were treated in our hospital and registered in the BREATH-NL Registry (NCT02815683) or participated in a clinical trial (NCT02022683) were included. A historical control group of patients treated in our hospital with a DLCO $\geq 20 \%$ pred was selected from the BREATH-NL Registry. These control patients were matched for sex, age, $\mathrm{FEV}_{1}$, and residual volume (RV). Dur-



Fig. 1. Study flowchart for patients with a DLCO $\leq 20 \%$ pred. EBV, endobronchial valve; SGRQ, St. George's Respiratory Questionnaire; 6MWT, 6-min walking test.

ing the selection process, all outcome parameters were blinded. All subjects signed informed consent.

\section{Measurements}

Post-bronchodilator spirometry, body plethysmography, and diffusion capacity were measured using the Jaeger MasterScreen ${ }^{\mathrm{TM}}$ (CareFusion, Germany) and were performed according to the ATS/ERS guidelines using the reference values from the European Community for Coal and Steel [12-14]. Spirometry and body plethysmography were performed at baseline and 6 months after treatment. The 6-min walking test was performed at baseline and 6 months and done in accordance with ATS recommendations [15]. The St. George's Respiratory Questionnaire (SGRQ) was used to measure health-related quality of life [16] and was obtained at baseline and 6 months follow-up. Arterial blood gas analysis, highresolution $\mathrm{CT}$ scan, quantitative $\mathrm{CT}$ analysis, and echocardiogram were performed at baseline.

\section{Treatment}

All bronchoscopic procedures were performed according to current best practice recommendations and all under general anesthesia [17]. A Chartis measurement (Chartis ${ }^{\circledR}$, Pulmonx Corporation, Redwood City, CA, USA) was performed to assess collateral ventilation between the target lobe and ipsilateral lobe(s). In the absence of collateral ventilation, EBV (Zephyr ${ }^{\circledR}$ EBV, Pulmonx Corporation, Redwood City, CA, USA) were placed in all segments or subsegments of the target lobe. 
Table 1. Baseline characteristics

\begin{tabular}{|c|c|c|}
\hline Baseline characteristic & $\begin{array}{l}\text { Patients with a DLCO } \\
\leq 20 \% \text { pred }(n=20)\end{array}$ & $\begin{array}{l}\text { Patients with a DLCO } \\
>20 \% \text { pred (historical matched } \\
\text { control group, } n=20 \text { ) }\end{array}$ \\
\hline Female, $n(\%)$ & $16(80)$ & $16(80)$ \\
\hline Age, years & $64 \pm 6$ & $62 \pm 7$ \\
\hline Body mass index & $21 \pm 2.7$ & $23 \pm 3.1$ \\
\hline Cigarette smoking, pack-years & $44 \pm 19$ & $51 \pm 27$ \\
\hline \multicolumn{3}{|l|}{$\mathrm{FEV}_{1}$} \\
\hline Liters & $0.58 \pm 0.14$ & $0.61 \pm 0.13$ \\
\hline $\begin{array}{l}\text { Percentage of predicted } \\
\text { FVC }\end{array}$ & $23 \pm 4$ & $24 \pm 4$ \\
\hline Liters & $2.15 \pm 0.74$ & $2.30 \pm 0.48$ \\
\hline Percentage of predicted & $70 \pm 17$ & $76 \pm 15$ \\
\hline \multicolumn{3}{|l|}{ RV } \\
\hline Liters & $5.26 \pm 0.92$ & $5.24 \pm 1.30$ \\
\hline \multicolumn{3}{|l|}{ TLC } \\
\hline Liters & $7.77 \pm 1.28$ & $7.77 \pm 1.50$ \\
\hline $\begin{array}{l}\text { Percentage of predicted } \\
\text { Ratio of RV to TLC, \% }\end{array}$ & $\begin{array}{c}141 \pm 13 \\
68 \pm 7\end{array}$ & $\begin{array}{c}142 \pm 18 \\
67 \pm 5\end{array}$ \\
\hline $\begin{array}{l}\text { Carbon monoxide diffusing capacity, } \\
\mathrm{mmoL} /(\min \times \mathrm{kPa})\end{array}$ & $\begin{array}{l}1.49 \pm 0.27 \\
18 \pm 1.6(\text { range } 14-20)\end{array}$ & $\begin{array}{l}2.31 \pm 0.65 \\
29 \pm 6\end{array}$ \\
\hline \multicolumn{3}{|l|}{ Arterial blood gas, $\mathrm{kPa}$} \\
\hline $\mathrm{PaO}_{2}$ & $8.4 \pm 1.2$ & $8.9 \pm 1.5$ \\
\hline $\mathrm{PaCO}_{2}$ & $5.6 \pm 0.7$ & $5.6 \pm 0.68$ \\
\hline $\mathrm{p}(\mathrm{A}-\mathrm{a}) \mathrm{O}_{2}$ gradient & $4.5 \pm 1.1$ & $4.1 \pm 1.5$ \\
\hline \multicolumn{3}{|l|}{6 -min walking test } \\
\hline Distance, $\mathrm{m}$ & $287 \pm 91$ & $320 \pm 82$ \\
\hline Pre-test oxygen saturation, $\%$ & $95 \pm 2$ & $95 \pm 2$ \\
\hline Post-test oxygen saturation, $\%$ & $86 \pm 7$ & $89 \pm 5$ \\
\hline \multicolumn{3}{|l|}{ Questionnaires } \\
\hline \multicolumn{3}{|l|}{ mMRC, points } \\
\hline 2 & $7(35 \%)$ & $5(25 \%)$ \\
\hline 3 & $9(45 \%)$ & $14(70 \%)$ \\
\hline 4 & $4(20 \%)$ & $1(5 \%)$ \\
\hline \multicolumn{3}{|l|}{ HRCT findings } \\
\hline \multicolumn{3}{|l|}{ Target lobe } \\
\hline RUL & 4 & 6 \\
\hline RUL+RML & 0 & 0 \\
\hline RML & 1 & 1 \\
\hline RLL & 3 & 5 \\
\hline LUL & 5 & 4 \\
\hline LLL & 7 & 4 \\
\hline Target lobe volume, $\mathrm{mL}$ & $1,698 \pm 439$ & $1,642 \pm 458$ \\
\hline Target lobe voxels below $-950 \mathrm{HU}, \%$ & $46 \pm 6$ & $44 \pm 6$ \\
\hline \multicolumn{3}{|l|}{ Emphysema distribution, $n(\%)$} \\
\hline Homogeneous & $13(65)$ & $12(60)$ \\
\hline Heterogeneous & $7(35)$ & $8(40)$ \\
\hline
\end{tabular}

Data represented as mean \pm SD unless otherwise specified. Heterogeneous emphysema was defined as a difference between the target lobe and ipsilateral lobe $(s) \geq 15 \%$ in voxels below $-950 \mathrm{HU}$ on HRCT. There were no statistically significant differences in baseline characteristics, with the exception of DLCO as per study design. $\mathrm{FEV}_{1}$, forced expiratory volume in $1 \mathrm{~s}$; FVC, forced vital capacity; RV, residual volume; TLC, total lung capacity; SGRQ, St. George's Respiratory Questionnaire; mMRC, modified Medical Research Counsel; HRCT, high-resolution computed tomography; RUL, right upper lobe; RML, right middle lobe; RLL, right lower lobe; LUL, left upper lobe; LLL, left lower lobe.

\section{Responders}

A patient was considered a responder to treatment if the $\mathrm{FEV}_{1}$, RV, 6-min walking distance (6MWD), or SGRQ improved more than the minimal clinically important difference (MCID) after treatment. The following MCIDs were used: relative change in $\mathrm{FEV}_{1} \geq 12 \%$, a decrease in RV of $\geq 430 \mathrm{~mL}$, an increase in $6 \mathrm{MWD}$ of $\geq 26 \mathrm{~m}$, and a decrease of SGRQ total score of 4 or 7 points [1822]. 
Table 2. Change in clinical outcomes 6 months after EBV treatment

\begin{tabular}{llll}
\hline Variable & $\begin{array}{l}\text { Patients with DLCO } \leq 20 \%, \\
6 \text { months FU }(n=17)\end{array}$ & $\begin{array}{l}\text { Patients with DLCO }>20 \%, \\
6 \text { months FU }(n=19)\end{array}$ & $\begin{array}{l}\text { DLCO } \leq 20 \text { vs. } \\
>20 \%, p \text { value }\end{array}$ \\
\hline FEV $_{1}$, L (relative increase, \%) & $+0.08 \pm 0.12(14 \pm 23)^{*}$ & $+0.18 \pm 0.16(28 \pm 20)$ & 0.09 \\
$\Delta$ FVC, L (relative increase, \%) & $+0.28 \pm 0.41(15 \pm 22)^{*}$ & $+0.48 \pm 0.60(22 \pm 25)$ & 0.40 \\
$\Delta$ RV, L (relative increase, \%) & $-0.45 \pm 0.95(-9 \pm 18)^{*}$ & $-0.74 \pm 0.78(-13 \pm 14)$ & 0.50 \\
$\Delta$ TLC, L (relative increase, \%) & $-0.25 \pm 0.69(-3 \pm 9)^{*}$ & $-0.38 \pm 0.52(-5 \pm 6)$ & 0.82 \\
$\Delta$ RV/TLC, \% & $-5 \pm 7^{*}$ & $-6 \pm 7$ & 0.53 \\
$\Delta$ GMWD, m & $+37 \pm 67^{*}$ & $+40 \pm 83$ & 0.93 \\
$\Delta$ SGRQ, points & $-12 \pm 14^{*}$ & $-10 \pm 16$ & 0.71 \\
\hline
\end{tabular}

Change in lung function, 6MWD and SGRQ total score after EBV treatment for patients with a DLCO $\leq 20 \%$ of predicted and patients with a DLCO $>20 \%$ of predicted. Data represented as mean \pm SD. FU, follow-up; FEV , forced expiratory volume in $1 \mathrm{~s}$; FVC, forced vital capacity; RV, residual volume; TLC, total lung capacity; 6MWD, 6-min walking distance; SGRQ, St. George's Respiratory Questionnaire. * Significant improvement within the DLCO $\leq 20 \%$ group over 6 months $(p<0.05)$. There were no significant differences between change in outcomes 6 months after treatments between patients with a DLCO $\leq 20 \%$ and the control group (DLCO $>20 \%$ ).

\section{Subanalyses}

Subanalyses were performed to assess whether there was a difference in outcome when patients (with a DLCO $\leq 20 \%$ pred) were divided into groups based on baseline partial pressure of oxygen in arterial blood on room air $\left(\mathrm{PaO}_{2} ; \geq 8.0 \mathrm{kPa}[60 \mathrm{~mm} \mathrm{Hg}]\right.$ or $<8.0$ $\mathrm{kPa})$, oxygen saturation $\left(\mathrm{StO}_{2}\right)$ post $6 \mathrm{MWD}(\geq 88$ or $<88 \%)$, distribution of emphysema (heterogeneous when difference between target and ipsilateral lobe voxels below -950 Hounsfield units on high-resolution CT scan $\geq 15$ percentage point, otherwise homogeneous), or presence of pulmonary hypertension (right ventricular peak pressure $<25$ or $\geq 25 \mathrm{~mm} \mathrm{Hg}$ on echocardiogram).

\section{Statistics}

A Wilcoxon signed ranks test was performed to evaluate the difference in lung function, exercise capacity, and quality of life between baseline and 6 months follow-up. A Mann-Whitney U test was performed for the comparison of outcome parameters between patients with a DLCO $\leq 20 \%$ vs. DLCO $>20 \%$ and also for the subgroup analyses. When follow-up data $\left(\mathrm{FEV}_{1}, \mathrm{RV}, 6 \mathrm{MWD}\right.$, or SGRQ) were missing, the patient was considered to be a nonresponder. A $p$ value of $<0.05$ was considered statistically significant. IBM SPSS Statistics version 23 (IBM, Armonk, NY, USA) was used for all analyses.

\section{Results}

Twenty patients with advanced COPD and a DLCO $\leq 20 \%$ pred underwent EBV treatment at our hospital ( $80 \%$ female, $58 \pm 8$ years, $\mathrm{FEV}_{1} 26 \pm 6 \%$ pred, RV $233 \pm$ $45 \%$ pred). See study flowchart in Figure 1, and baseline characteristics in Table 1. Except for DLCO $(p<0.001)$, there were no significant differences between baseline characteristics for the patient group with a DLCO $\leq 20 \%$ pred and the control group with a DLCO $>20 \%$ pred (Table 1).

At 6 months follow-up, there was a statistically significant improvement in all lung function parameters, $6 \mathrm{MWD}$, and the SGRQ total score compared to baseline measurements (Table 2). RV ( $-0.45 \pm 0.95 \mathrm{~L}), 6 \mathrm{MWD}$ (38 $\pm 65 \mathrm{~m})$, and SGRQ score ( $-12 \pm 13$ points) improved more than the MCID. This was not the case for $\mathrm{FEV}_{1}(0.08$ $\pm 0.12 \mathrm{~L})$. Responder rates at 6 months for the patient group with a DLCO $\leq 20 \%$ pred for $\mathrm{FEV}_{1}$, RV, SGRQ ( -4 points), SGRQ (-7 points), and $6 \mathrm{MWD}$ were $45,40,65$, 50 , and $45 \%$, respectively (Fig. 2). There were no statistically significant differences in lung function parameters, 6MWD, SGRQ total score, and responder rate between the patient group with a DLCO $\leq 20 \%$ pred and the control group with a DLCO $>20 \%$ pred (Table 2 ).

No patients died in both the group of patients with a DLCO $\leq 20 \%$ pred and the control group during 6 month follow-up. In the group of patients with a DLCO $\leq 20 \%$ pred, a pneumothorax, for which a chest tube insertion was needed, did occur in 3 cases (15\%), all within 4 days after the procedure. In one of these cases, temporary removal of EBV and video-assisted thoracic surgery was additionally performed to resolve the pneumothorax. Three other patients had a small pneumothorax not requiring intervention. Three patients developed a COPD exacerbation requiring hospital admission (15\%). Three patients (15\%) required additional bronchoscopies for valve replacement. One patient (5\%) required removal of all valves be- 
Table 3. Serious adverse events after EBV treatment

\begin{tabular}{|c|c|c|c|}
\hline Serious adverse event & $\begin{array}{l}\text { SAEs in patients with } \\
\text { a DLCO } \leq 20 \% \\
(n=20), n(\%)\end{array}$ & $\begin{array}{l}\text { SAEs in patients with } \\
\text { a DLCO }>20 \% \text { pred } \\
(n=20), n(\%)\end{array}$ & $\begin{array}{l}\text { Reported SAEs [4-8] } \\
\text { in the literature, } \\
\min -\max \%\end{array}$ \\
\hline \multicolumn{4}{|l|}{ Pneumothorax } \\
\hline Requiring chest tube drainage & $3(15)$ & $2(10)$ & $14.7-29.6$ \\
\hline Hospital admission for COPD exacerbation & $3(15)$ & $1(5)$ & $9.8-34.9$ \\
\hline For permanent removal of valves & $1(5)$ & $1(5)$ & $1.5-20.5$ \\
\hline Pneumonia & $0(0)$ & $2(10)$ & $0-10$ \\
\hline Death & $0(0)$ & $0(0)$ & $1.5-10$ \\
\hline
\end{tabular}

Serious adverse events (SAEs) during 6 months follow-up for patients with a DLCO $\leq 20 \%(n=20)$ and patients with a DLCO $>20 \%$ pred $(n=20)$ and reported SAEs in RCTs investigating bronchoscopic lung volume reduction with endobronchial valves with a 3-12-month follow-up. There were no statistically significant differences between SAEs for patients with a DLCO $\leq 20 \%$ and patients with a DLCO $>20 \%$ pred.

Fig. 2. Responder rates at 6 months followup for patients with a DLCO $\leq 20 \%$ pred $(n=20)$ and DLCO $>20 \%$ pred $(n=20)$. Responders were defined as having an improvement equal to or greater than the minimal clinically important difference for $\mathrm{FEV}_{1}(\geq 12 \%)$ [18], RV ( $\left.\geq 430 \mathrm{~mL}\right)$ [19], SGRQ ( $\geq 4$ points) [21], SGRQ ( $\geq 7$ points) [22], or 6MWD ( $\geq 26 \mathrm{~m})$ [20]. There were no significant differences in responder rates for patients with a DLCO $\leq 20 \%$ pred and DLCO $>20 \%$ pred. $\mathrm{FEV}_{1}$, forced expiratory volume in $1 \mathrm{~s}$; RV, residual volume; 6MWD, 6-min walking distance; SGRQ, St. George's Respiratory Questionnaire.

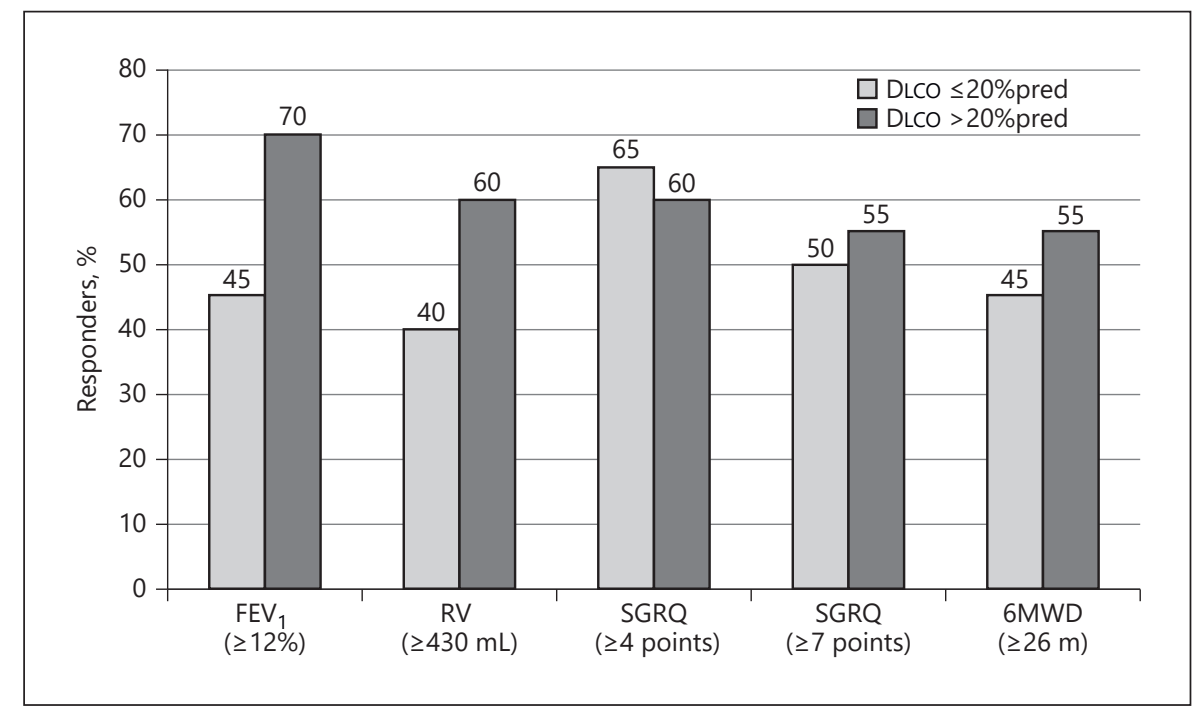

cause of valve migration and consequently loss of atelectasis due to extensive granulation tissue. No pneumonias were reported. No statistically significant differences were found for SAEs between the patients with a DLCO $\leq 20 \%$ pred and the control group (Table 3 ).

Subgroup analyses for patients with a DLCO $\leq 20 \%$ pred divided into groups based on emphysema distribution (homogeneous $n=11$; heterogeneous $n=5$ ), baseline $\mathrm{PaO}_{2}(\geq 8.0 \mathrm{kPa} n=11 ;<8.0 \mathrm{kPa} n=5)$, baseline $\mathrm{StO}_{2}$ after 6 -min walking test $(\geq 88 \% n=9 ;<88 \% n=7)$ and presence of pulmonary hypertension on baseline echocardiography (RV peak pressure $<25 \mathrm{~mm} \mathrm{Hg} n=6$; RV peak pressure $\geq 25 \mathrm{~mm} \operatorname{Hg} n=10$ ) revealed no statistically sig- nificant differences for change in lung function parameters, SGRQ scores, and 6MWD at 6 months follow-up, with the exception of improvement of forced vital capacity (FVC) in participants without pulmonary hypertension versus participants with pulmonary hypertension $(\Delta \mathrm{FVC}+0.53 \pm 0.29$ L vs. $+0.14 \pm 0.42 \mathrm{~L}, p=0.045)$.

\section{Discussion/Conclusion}

To our knowledge, this is the first study investigating EBV treatment in COPD patients with a very low DLCO, that is, $20 \%$ pred or lower. We found a statistically signif- 
icant improvement of lung function, $6 \mathrm{MWD}$, and quality of life 6 months after EBV treatment. Improvement of $\mathrm{RV}, 6 \mathrm{MWD}$, and SGRQ score were greater than the established MCID. Furthermore, there were no statistically significant differences in change in lung function, 6MWD, SGRQ, and responder rates and SAEs between the low DLCO group and the matched control group with a DLCO $>20 \%$ pred. The most common SAE was a pneumothorax requiring chest drainage (15\%). Subanalyses of patients with a DLCO $\leq 20 \%$ pred divided into groups based on baseline characteristics that associate with reduced oxygen uptake and emphysema distribution showed no relevant differences on these outcomes.

There was a trend towards a larger increase in $\mathrm{FEV}_{1}$ in patients with a DLCO $>20$ vs. $\leq 20 \%$ pred $(+0.18 \pm 0.16$ vs. $+0.08 \pm 0.12, p=0.08)$ and a higher responder rate for $\mathrm{FEV}_{1}$ in the DLCO $>20 \%$ pred group $\left(\mathrm{FEV}_{1} 70\right.$ vs. $45 \%$, $p=0.11)$, but notably this was not reflected in a greater improvement in exercise capacity (6MWD) or quality of life (SGRQ).

A recently published pooled analysis of 6 randomized controlled trials investigating EBV treatment (in patients with a DLCO $\geq 20 \%$ pred) showed an improvement in $\mathrm{FEV}_{1}(+21.8 \%$ relative increase), RV $(-0.58 \mathrm{~L}), 6 \mathrm{MWD}$ $(+49 \mathrm{~m})$, and SGRQ score (-9.1 points) 3-12 months after EBV treatment [23]. These results are somewhat better than our 6-month follow-up results for patients with a DLCO $\leq 20 \%$ pred $\left(\mathrm{FEV}_{1}+16 \%\right.$ relative increase, $\mathrm{RV}$ $-0.45 \mathrm{~L}, 6 \mathrm{MWD}+38 \mathrm{~m}$, SGRQ -12 points). This may be explained by the fact that only patients with heterogeneous emphysema were included in 4 of the 6 trials, whereas in our study, $65 \%$ of patients with a DLCO $\leq 20 \%$ pred had a homogeneous distribution of emphysema.

The responder rates for $\mathrm{FEV}_{1}, \mathrm{RV}, \mathrm{SGRQ}$ ( -4 points), and $6 \mathrm{MWD}$ for patients with a DLCO $\leq 20 \%$ pred at 6 months follow-up were $45,40,65$, and $45 \%$, respectively. The responder rates are within the range of responder rates published in recent RCTs $\left(\mathrm{FEV}_{1} 37-72 \%\right.$, SGRQ $56-$ $79 \%$, and 6 MWD $42-87 \%$ ) [4, 6-8], with the exception of responder rate for RV, which is slightly lower (44-71\%). It is important to note that our responder rates may be a conservative estimate, since all participants with missing data were considered to be nonresponders. Furthermore, for patients with severe COPD, an MCID of 7 points on SGRQ total score has been shown to be more applicable to this patient group and treatment [22]. The incidence rate of SAEs in the patients group with a DLCO $\leq 20 \%$ pred was comparable to recent literature investigating EBV treatment (Table 3) [4-8].
In studies investigating EBV treatment, patients with a very low DLCO were often excluded. This may not be surprising since DLCO has been associated with an increased likelihood of hypoxemia and is a known unfavorable prognostic factor in COPD $[24,25]$. Furthermore, as mentioned in the introduction, the multicenter NETT trial investigating lung volume reduction surgery identified a group of high-risk patients with an $\mathrm{FEV}_{1}<20 \%$ pred and either a homogeneous distributed emphysema or a DLCO $\leq 20 \%$ who had increased 30 -day mortality rates (16\%) [9]. However, patients fulfilling the NETT high risk criteria have more recently been demonstrated to be able to have good effects from lung volume reduction surgery with no increased mortality rate $[11,26]$. Furthermore, EBV treatment in patients with a $\mathrm{FEV}_{1} \leq 20 \%$ pred has been shown to be safe and effective [27, 28], and our study shows good results for EBV treatment in patients with a DLCO $\leq 20 \%$ pred.

The measurement of DLCO is used as an indication for functional gas exchange surface in the lung [29]. In emphysema, there is loss of gas exchange surface, and an inverse linear relation between DLCO and severity of emphysema on CT has been established [30]. However, in COPD, other factors such as ventilation/perfusion (V/Q) disturbances, inhomogeneous ventilation, and airway obstruction can influence the outcome of the DLCO measurement both negatively and positively [31-33]. The measured DLCO for a patient with COPD is therefore likely to be a balance of these factors. COPD is a heterogeneous disease, so while in one patient, the outcome of DLCO may be mainly due to loss of gas exchange surface, in the next patient, airway obstruction and V/Q disturbances may be the driving factors influencing DLCO.

We propose that the chance of successful EBV treatment in patients with a very low DLCO is related to the balance of factors causing the DLCO to be low. Factors we consider favorable in clinical practice are a high destruction level of the target lobe on chest CT and an $\mathrm{FEV}_{1}$ larger than $20 \%$ of the predicted value. Factors we consider unfavorable are a homogeneous distribution of emphysema, significant target lobe perfusion, an important hypoxemia (i.e., $\mathrm{PaO}_{2}<8.0 \mathrm{kPa}$ or $60 \mathrm{~mm} \mathrm{Hg}$ ), significant desaturation during exercise, and pulmonary hypertension. We take every factor into account, and no single factor is an absolute contraindication. It is important to note that there is no scientific literature to support the use of these factors for clinical decision-making.

Our study did have some limitations. First of all, this is a retrospective analysis. However, we did include a well-matched control group with a significantly higher 
DLCO to compare outcome parameters to. Furthermore, to prevent selection bias as much as possible, all patients with a DLCO $\leq 20 \%$ pred who underwent EBV treatment in our hospital were included. Nevertheless, there were emphysema patients with a very low DLCO, who were assessed but not accepted for EBV treatment. Another limitation is that our group of patients is relatively small. For the subgroup analyses that were performed, the number of patients was likely too small to exclude relevant statistically significant differences. Also, the factors for which subanalyses were performed are also factors we take into account in our clinical decision-making whether or not to treat an individual patient. However, since only a minority of patients with COPD who undergo EBV treatment have a DLCO $\leq 20 \%$ pred, it may be challenging to investigate a larger group of patients. Furthermore, there is a risk of bias because of missing data. Therefore, as mentioned above, with regard to responder rates, we considered participants to be nonresponders if data was missing. Finally, since no measurement of DLCO or arterial blood gas analysis was performed during follow-up, no information is available on change in DLCO or gas exchange after EBV treatment.

In conclusion, we found statistically significant and clinically relevant improvements in lung function, exercise capacity, and quality of life up to 6 months after EBV treatment in COPD patients with a DLCO $\leq 20 \%$ pred, with no increased risk of SAEs in this single-center retrospective analysis. No factors influencing the chance of a successful treatment could be identified in this group of participants. However, since the investigated subgroups were small, it is too soon to draw any definitive conclu- sions on the latter subject. It would be interesting to investigate whether long-term follow-up of EBV treatment is comparable for COPD patients with and without a very low DLCO. Furthermore, future research investigating factors influencing the likeliness of successful EBV treatment in COPD patients with a very low DLCO could greatly help clinicians in deciding whether or not EBV treatment is suitable for their patient.

\section{Statement of Ethics}

All patients signed informed consent and this study was approved by the Ethics Committee (NCT02815683 and NCT02022683).

\section{Disclosure Statement}

M.v.D., J.E.H., K.K., N.H.T.T.H., and H.A.M.K. have no conflict of interest. D.-J.S. is an investigator, physician advisor, and consultant for PulmonX Inc. CA, USA. No funding was received for this study.

\section{Author Contributions}

M.v.D. contributed to the trial design, analysis of data, preparation of the "Results" section and tables, and the writing of the manuscript and is the guarantor of the manuscript. J.E.H. contributed to the analysis of the data and the discussion and revisions of the manuscript. K.K. contributed to the discussion and revisions of the manuscript. N.H.T.T.H. contributed to the discussion and revisions of the manuscript. H.A.M.K. contributed to the discussion and revisions of the manuscript. D.-J.S. contributed to the trial design and the discussion and revisions of the manuscript.

\section{References}

1 Janssen DJ, Wouters EF, Spruit MA. Psychosocial consequences of living with breathlessness due to advanced disease. Curr Opin Support Palliat Care. 2015 Sep;9(3):232-7.

2 Singh D, Agusti A, Anzueto A, Barnes PJ, Bourbeau J, Celli BR, et al. Global Strategy for the Diagnosis, Management, and Prevention of Chronic Obstructive Lung Disease: the GOLD science committee report 2019. Eur Respir J. 2019 May 18;53(5):pii: 1900164.

3 Herth FJ, Slebos DJ, Criner GJ, Valipour A, Sciurba F, Shah PL. Endoscopic Lung Volume Reduction: An Expert Panel Recommendation - Update 2019. Respiration. 2019;97(6): 548-57.

4 Criner GJ, Sue R, Wright S, Dransfield M, Rivas-Perez H, Wiese T, et al.; LIBERATE Study Group. A Multicenter Randomized Con- trolled Trial of Zephyr Endobronchial Valve Treatment in Heterogeneous Emphysema (LIBERATE). Am J Respir Crit Care Med. 2018 Nov;198(9):1151-64.

5 Davey C, Zoumot Z, Jordan S, McNulty WH, Carr DH, Hind MD, et al. Bronchoscopic lung volume reduction with endobronchial valves for patients with heterogeneous emphysema and intact interlobar fissures (the BeLieVeRHIFi study): a randomised controlled trial. Lancet. 2015 Sep;386(9998):1066-73.

6 Kemp SV, Slebos DJ, Kirk A, Kornaszewska $\mathrm{M}$, Carron K, Ek L, et al.; TRANSFORM Study Team *. A Multicenter Randomized Controlled Trial of Zephyr Endobronchial Valve Treatment in Heterogeneous Emphysema (TRANSFORM). Am J Respir Crit Care Med. 2017 Dec;196(12):1535-43.
7 Klooster K, ten Hacken NH, Hartman JE, Kerstjens HA, van Rikxoort EM, Slebos DJ. Endobronchial Valves for Emphysema without Interlobar Collateral Ventilation. N Engl J Med. 2015 Dec;373(24):2325-35.

8 Valipour A, Slebos DJ, Herth F, Darwiche K, Wagner M, Ficker JH, et al.; IMPACT Study Team. Endobronchial Valve Therapy in Patients with Homogeneous Emphysema. Results from the IMPACT Study. Am J Respir Crit Care Med. 2016 Nov;194(9): 1073-82.

9 Fishman A, Fessler H, Martinez F, McKenna RJ Jr, Naunheim K, Piantadosi S, et al.; National Emphysema Treatment Trial Research Group. Patients at high risk of death after lung-volume-reduction surgery. $\mathrm{N}$ Engl J Med. 2001 Oct;345(15):1075-83. 
10 Fishman A, Martinez F, Naunheim K, Piantadosi S, Wise R, Ries A, et al.; National Emphysema Treatment Trial Research Group. A randomized trial comparing lung-volume-reduction surgery with medical therapy for severe emphysema. N Engl J Med. 2003 May; 348(21):2059-73.

11 Caviezel C, Schaffter N, Schneiter D, Franzen D, Inci I, Opitz I, et al. Outcome After Lung Volume Reduction Surgery in Patients With Severely Impaired Diffusion Capacity. Ann Thorac Surg. 2018 Feb;105(2):379-85.

12 Miller MR, Hankinson J, Brusasco V, Burgos F, Casaburi R, Coates A, et al.; ATS/ERS Task Force. Standardisation of spirometry. Eur Respir J. 2005 Aug;26(2):319-38.

13 Wanger J, Clausen JL, Coates A, Pedersen OF, Brusasco V, Burgos F, et al. Standardisation of the measurement of lung volumes. Eur Respir J. 2005 Sep;26(3):511-22.

14 Stocks J, Quanjer PH; Official Statement of The European Respiratory Society. Reference values for residual volume, functional residual capacity and total lung capacity. ATS Workshop on Lung Volume Measurements. Eur Respir J. 1995 Mar;8(3):492-506.

15 ATS Committee on Proficiency Standards for Clinical Pulmonary Function Laboratories. ATS statement: guidelines for the six-minute walk test. Am J Respir Crit Care Med. 2002 Jul;166(1):111-7.

16 Jones PW, Quirk FH, Baveystock CM, Littlejohns P. A self-complete measure of health status for chronic airflow limitation. The St. George's Respiratory Questionnaire. Am Rev Respir Dis. 1992 Jun;145(6):1321-7.

17 Slebos DJ, Shah PL, Herth FJ, Valipour A. Endobronchial Valves for Endoscopic Lung Volume Reduction: Best Practice Recommendations from Expert Panel on Endoscopic Lung Volume Reduction. Respiration. 2017;93(2): $138-50$.
18 Donohue JF. Minimal clinically important differences in COPD lung function. COPD. 2005 Mar;2(1):111-24.

19 Hartman JE, Ten Hacken NH, Klooster K, Boezen HM, de Greef MH, Slebos DJ. The minimal important difference for residual volume in patients with severe emphysema. Eur Respir J. 2012 Nov;40(5):1137-41.

20 Puhan MA, Chandra D, Mosenifar Z, Ries A, Make B, Hansel NN, et al.; National Emphysema Treatment Trial (NETT) Research Group. The minimal important difference of exercise tests in severe COPD. Eur Respir J. 2011 Apr;37(4):784-90.

21 Jones PW. St. George's Respiratory Questionnaire: MCID. COPD. 2005 Mar;2(1):75-9.

22 Welling JB, Hartman JE, Ten Hacken NH, Klooster K, Slebos DJ. The minimal important difference for the St George's Respiratory Questionnaire in patients with severe COPD. Eur Respir J. 2015 Dec;46(6):1598-604.

23 van Geffen WH, Slebos DJ, Herth FJ, Kemp SV, Weder W, Shah PL. Surgical and endoscopic interventions that reduce lung volume for emphysema: a systemic review and metaanalysis. Lancet Respir Med. 2019 Apr;7(4): 313-24.

24 Boutou AK, Shrikrishna D, Tanner RJ, Smith C, Kelly JL, Ward SP, et al. Lung function indices for predicting mortality in COPD. Eur Respir J. 2013 Sep;42(3):616-25.

25 Mohsenifar Z, Lee SM, Diaz P, Criner G, Sciurba F, Ginsburg M, et al. Single-breath diffusing capacity of the lung for carbon monoxide: a predictor of $\mathrm{PaO} 2$, maximum work rate, and walking distance in patients with emphysema. Chest. 2003 May;123(5):1394-400.
26 Meyers BF, Yusen RD, Guthrie TJ, Patterson GA, Lefrak SS, Davis GE, et al. Results of lung volume reduction surgery in patients meeting a national emphysema treatment trial highrisk criterion. J Thorac Cardiovasc Surg. 2004 Mar;127(3):829-35.

27 Darwiche K, Karpf-Wissel R, Eisenmann S, Aigner C, Welter S, Zarogoulidis $\mathrm{P}$, et al. Bronchoscopic Lung Volume Reduction with Endobronchial Valves in Low-FEV1 Patients. Respiration. 2016;92(6):414-9.

28 Trudzinski FC, Höink AJ, Leppert D, Fähndrich S, Wilkens H, Graeter TP, et al. Endoscopic Lung Volume Reduction Using Endobronchial Valves in Patients with Severe Emphysema and Very Low FEV1. Respiration. 2016;92(4):258-65.

29 Hughes JM, Bates DV. Historical review: the carbon monoxide diffusing capacity (DLCO) and its membrane (DM) and red cell (Theta. Vc) components. Respir Physiol Neurobiol. 2003 Nov;138(2-3):115-42.

30 Nambu A, Zach J, Schroeder J, Jin GY, Kim SS, Kim YI, et al. Relationships between diffusing capacity for carbon monoxide (DLCO), and quantitative computed tomography measurements and visual assessment for chronic obstructive pulmonary disease. Eur J Radiol. 2015 May;84(5):980-5.

31 Thompson BR, Kim Prisk G, Peyton P, Pierce RJ, Rochford PD. Inhomogeneity of ventilation leads to unpredictable errors in measured D(L)CO. Respir Physiol Neurobiol. 2005 Apr; 146(2-3):205-14

32 Prediletto R, Fornai E, Catapano G, Carli C. Assessment of the alveolar volume when sampling exhaled gas at different expired volumes in the single breath diffusion test. BMC Pulm Med. 2007 Dec 19;7:18.

33 Graham BL, Mink JT, Cotton DJ. Overestimation of the single-breath carbon monoxide diffusing capacity in patients with air-flow obstruction. Am Rev Respir Dis. 1984 Mar; 129(3):403-8. 